\title{
Using a Finite Element Pediatric Hip Model in Clinical Evaluation - A Feasibility Study
}

Skytte $\mathrm{TL}^{1}$, Mikkelsen LP ${ }^{2}$, Sonne-Holm $\mathbf{S}^{1}$ and Wong $\mathbf{C}^{1 *}$

${ }^{1}$ Department of Orthopaedics, University Hospital of Hvidovre, Kettegard Alle 30, Hvidovre, Denmark

${ }^{2}$ Composits and Materials Mechanics, Technical University of Denmark, Frederiksborgvej 399, Roskilde, Denmark

\begin{abstract}
The paper describe a method to construct a finite element model of the hip joint of a child based on clinical recorded CT data. A model which can be used for diagnostic aid and pre-operative surgical evaluation. First part of this development is a feasibility study of this method. A scan of the asymptomatic left hip of a 10-year-old girl with a dysplastic right hip was used. Cartilage was not visible why it was modeled as an interaction with constant thickness between two surfaces. For every point on the acetabular and femoral bone surfaces, the shortest distance to the other surface was used to calculate the resulting stress in the normal direction. At a load of $233 \%$ BW the model predicted peak pressures in the hip joint of 9.7-13.8 MPa and an area in contact of 351-405 $\mathrm{mm}^{2}$. Experimental validation using the hip joint of a child was not ethical viable. Instead, our results were compared to previous published experimental studies and computational models investigating the adult hip joint. Good correlation between the current model and previous models were found. The current case specific modeling technique may be a useful complement to the previously developed hip models.
\end{abstract}

Keywords: Finite element; Hip joint cartilage; Pediatric child

\section{Introduction}

Several studies indicate that the development of hip osteoarthritis (OA) is strongly correlated with malformations of the hip joint [13]. Malformations of the joint may lead to elevated cartilage contact stresses increasing the risk of developing OA [4]. Human in vivo studies of the hip joint are important to increase our knowledge regarding the mechanics leading to $\mathrm{OA}$, but they are difficult and unethical to conduct. Instead several three-dimensional finite element (FE) models have been constructed to evaluate the biomechanics of the mature human pelvis and hip joint. Some studies combined experimental trials with $\mathrm{FE}$ analyses in order to validate the stress distribution in the pelvic cortical bone or contact forces in the articular cartilage of FE models [5-7]. Harris et al. constructed FE models of 10 hips and found large variations among subjects when considering contact forces in the articular cartilage [8]. Most FE models to date were constructed from an adult or elderly hip. To the knowledge of the authors, only Kim et al. used the hip from a 10-year-old girl to construct their FE model [9]. It is of significant relevance to construct FE models of the patient specific pediatric hip, because congenital malformations are believed to be of importance in the development of OA [8]. These FE models could be used to investigate preventive treatments of $\mathrm{OA}$, which is ethical unfeasible in in vivo studies.

Geometry for FE models were mainly based on post mortem recorded data or computed tomography (CT) scanning with a contrast agent injected into the joint cavity to visualize the cartilage layers $[8,10]$. Majumder et al. used in situ CT scan data to construct their FE model, but they assumed the femoral head and the acetabulum to be rigidly connected [11]. The aim of the current study, is to construct a realistic FE model of the hip joint of a child using standard preoperative CT scan data. A potentially useful tool for surgeons, when planning surgery strategies of dysplastic hips, since our current state of knowledge in the mechanical consequences of hip luxation, related surgeries and, most of all, indications to the latter are limited [12]. Compared to previous models, this model is a more useful tool in the clinic because:

- A model is created from standard pre-operative CT scan data.

- It is relatively quick to construct a patient specific model, because only the geometrical structure of the bones is patient specific.

This study will investigate if our method is feasible, and for this purpose our FE generated output, were compared to findings from published experimental studies and computational models.

\section{Materials and Methods}

CT scan of the hip of a 10-year-old girl was performed as part of the clinical treatment protocol. A body weight (BW) of $\mathrm{kg}$ was used throughout the paper. In the specific case the right hip was found to be slightly dysplastic while the left hip was evaluated as normal with an acetabular index (AI) of 14.7 and a centre edge (CE) angle of $33.5^{\circ}$. Normal values for a 10 -year-old are AI $=9.1 \pm 4.6$ and CEangle $=32.6^{\circ} \pm 6.0^{\circ}$ (mean $\left.\pm \mathrm{SD}\right)$. The evaluation was made by two experienced pediatric orthopedics. The left asymptomatic hip was used as the basis for the current FE model. Four different models were created based on the bone geometry from the 10-year-old girl: (1) adult's bone mechanical properties (greater stiffness and yield stress) and cartilage thickness of $5.0 \mathrm{~mm},(2)$ adult's bone mechanical properties and cartilage thickness of $2.7 \mathrm{~mm}$, (3) children's bone mechanical properties (lower stiffness and yield stress) and cartilage thickness of $5.0 \mathrm{~mm}$ and (4) children's bone mechanical properties and cartilage thickness of $2.7 \mathrm{~mm}$. The geometrical structure of the bones were the same in all four models.

\section{Challenges}

CT scan of the hip of a 10-year-old girl was performed as part

*Corresponding author: Wong C, Department of Orthopaedics, University Hospital of Hvidovre, Kettegard Alle 30, 2650 Hvidovre, Denmark, Tel: +45 3632 23 33; E-mail: chwo123@gmail.com

Received: November 27, 2017; Accepted: December 24, 2017; Published: December 31, 2017

Citation: Skytte TL, Mikkelsen LP, Sonne-Holm S, Wong C (2017) Using a Finite Element Pediatric Hip Model in Clinical Evaluation - A Feasibility Study. J Bioengineer \& Biomedical Sci 7: 241. doi: 10.4172/2155-9538.1000241

Copyright: $\odot 2017$ Skytte TL, et al. This is an open-access article distributed under the terms of the Creative Commons Attribution License, which permits unrestricted use, distribution, and reproduction in any medium, provided the original author and source are credited. 
of the clinical treatment protocol. A body weight (BW) of $32 \mathrm{~kg}$ was used throughout the paper. In the specific case the right hip was found to be slightly dysplastic while the left hip was evaluated as normal with an acetabular index (AI) of 14.7 and a centre edge (CE) angle of $33.5^{\circ}[3,13]$. Normal values for a 10 -year-old are $\mathrm{AI}=9.1 \pm 4.6$ and $\mathrm{CE}$-angle $=32.6^{\circ} \pm 6.0^{\circ}($ mean $\pm \mathrm{SD})$ [14]. The evaluation was made by two experienced pediatric orthopedics. The left asymptomatic hip was used as the basis for the current FE model. Four different models were created based on the bone geometry from the 10-year-old girl:

(1) Adult's bone mechanical properties (greater stiffness and yield stress) and cartilage thickness of $5.0 \mathrm{~mm},(2)$ Adult's bone mechanical properties and cartilage thickness of $2.7 \mathrm{~mm}$, (3) Children's bone mechanical properties (lower stiffness and yield stress) and cartilage thickness of $5.0 \mathrm{~mm}$ and (4) Children's bone mechanical properties and cartilage thickness of $2.7 \mathrm{~mm}$. The geometrical structure of the bones were the same in all four models.

\section{Model generation}

The geometry of the bone was segmented from CT using ScanIP+FE 5.1 (Simpleware, Exeter, UK). The segmentation was mainly automatic using gray scale values. Morphological filters and smoothing of the surfaces were used. The cortical bone was assigned a thickness of approximately $2 \mathrm{~mm}$ and a stiffness of $\mathrm{E}=17.0 \mathrm{GPa}$ [15]. No correlation between Hounsfield Unit (HU) and density was available for the current data. Instead, the density $\left(\rho\left[\mathrm{gcm}^{-3}\right]\right)$ of the trabecular bone was assumed to be within the range of $\rho=0.1-0.7 \mathrm{~g}$ $\mathrm{cm}^{-3.37}$ A linear relationship between $\mathrm{HU}$ and density was used [11]. Stiffness $(\mathrm{E}[\mathrm{MPa}])$ of trabecular bone were dependent of density by $\mathrm{E}=2017.3 \mathrm{MPa}$

- $(\rho / \rho 0)^{2.46}$ for the pelvic bone16 and $\mathrm{E}=1157 \mathrm{MPa}$

$\cdot(\rho / \rho 0)^{1.78}$ for the femoral bone37, where $\rho 0=1 \mathrm{~g} / \mathrm{cm}^{3}$

Cortical and trabecular bone were assigned plastic material properties with yield stress ( $\sigma y,[\mathrm{MPa}])$ corresponding to the compressive strengths reported by Wirtz et al. [15]. Material properties and numbers of elements are listed in Table 1. Ohman et al. (2011) found that children's femoral cortical bone had significant lower compressive Young's modulus (-34\%) and yield stress (-38\%), but higher compressive ultimate strain $(+24 \%)$ than the adult bone tissue. Therefore models with bone mechanical properties of a child were also created. Stiffness and yield stress of trabecular bone were scaled using the findings by $\mathrm{O}^{*}$ hman et al. (Table 2) [4].

\section{Boundary conditions and loading}

The geometry was exported as an orphan mesh to Abaqus 6.133 (Simulia Corp., Providence, RI, USA). The positions of pelvis and femur during the scan were maintained. Nodes at the pubis symphysis, sacroiliac joint and the superior rim of the pelvis were fixed as a reference position (Figure 1). Boundaries were picked far from the acetabulum to ensure the output of interest was not influenced. The distal part of the femoral bone was constrained by four springs with a spring stiffness of $10 \mathrm{~N} / \mathrm{mm}$, but was otherwise free to translate and rotate. Load was applied to the center of the femoral head using directions found by Bergmann et al. [16]. They reported a maximum load of $233 \%$ BW during normal walking (medial $=52 \%$, anterior $=32 \%$, superior $=225 \%$ ). The direction was maintained while the magnitude was scaled from $50 \%$ to $300 \%$ BW. Only one loading direction was used because Harris et al. found greater variation among subjects than among loading scenarios [16]. Muscles and

\begin{tabular}{|c|c|c|}
\hline Material & Property & Reference \\
\hline \multirow{5}{*}{$\begin{array}{l}\text { Cortical bone } \\
\text { (pelvic and } \\
\text { femoral) }\end{array}$} & $\begin{array}{l}\text { Linear elastic plastic, isotropic, } \\
\text { homogeneous Stiffness, } \mathrm{E}=17.0 \mathrm{GPa}\end{array}$ & \multirow{5}{*}[14,25]{} \\
\hline & Poisson's ratio, v=0.29 & \\
\hline & Yield stress, ay=70-100 MPa & \\
\hline & No. elements (pelvis)=94 141 & \\
\hline & No. elements (femur) $=36754$ & \\
\hline \multirow{5}{*}{$\begin{array}{l}\text { Pelvic } \\
\text { trabecular } \\
\text { bone }\end{array}$} & Linear elastic plastic, isotropic & \multirow{5}{*}[6,7,14]{} \\
\hline & Stiffness, $E=9-506 \mathrm{MPa}$ & \\
\hline & Poisson's ratio, $\|=0.2$ & \\
\hline & Yield stress ay=1-13 Mpa & \\
\hline & No. elements $=95405$ & \\
\hline \multirow{3}{*}{$\begin{array}{l}\text { Femoral } \\
\text { trabecular } \\
\text { bone }\end{array}$} & $\begin{array}{l}\text { Linear elastic, isotropic Stiffness, } E=23 \text { - } \\
508 \mathrm{MPa} \text { Poisson's ratio, } \mathrm{v}=0.2\end{array}$ & \multirow[t]{3}{*}[14,31]{} \\
\hline & Yield stress, $a_{y}=1-13 \mathrm{MPa}$ & \\
\hline & No. elements $=45745$ & \\
\hline \multirow{3}{*}{ Cartilage } & $\begin{array}{c}\text { Hyper-elastic neo-Hookean (eq. } 1 \text { ) } \\
\text { Shear modulus, } a=6.8 \mathrm{MPa} \text { Poisson's } \\
\text { ratio, } v=0.490\end{array}$ & \multirow[t]{3}{*}[1,7,10,12,13]{} \\
\hline & Thickness $=5.0 \mathrm{~mm}$ & \\
\hline & OR Thickness $=2.7 \mathrm{~mm}$ & \\
\hline
\end{tabular}

Table 1: Material properties used in the adult-property models.

\begin{tabular}{|c|c|c|}
\hline Material & Property & Reference \\
\hline \multirow{2}{*}{ Cortical bone } & Stiffness, E=11.8 GPa & \multirow{2}{*}{ Ohman et al. [4] } \\
\cline { 2 - 3 } & Yield stress, o-y=78-146 MPa & \\
\hline \multirow{2}{*}{ Pelvic bone trabecular } & Stiffness, E=6-324 MPa & Scaled using \\
\cline { 2 - 3 } & Yield stress, o-y=0.6-8 MPa & Ohman et al. [4] \\
\hline \multirow{2}{*}{ Femoral bone trabecular } & Stiffness, E=15-325 MPa & $\begin{array}{c}\text { Scaled using } \\
\text { Ohman et al. [4] }\end{array}$ \\
\cline { 2 - 3 } & Yield stress, o-y=0.6-8 MPa & \\
\hline
\end{tabular}

Table 2: Material properties used in the child-property models. Properties are only stated if different from the adult properties listed in Table 1.

ligaments were not included in the model. Instead, their effect on the hip joint was replaced by applying the load to the femoral head [17]. To avoid rigid rotations and improve stability, 12 springs were applied around the joint $(\mathrm{k}=1 \mathrm{~N} / \mathrm{mm})$. Analyses were conducted in Abaqus/Explicit. Explicit analyses are efficient for large models and have a robust contact algorithm. Because explicit problems are solved as wave propagation problems, waves of stress in the model are seen. The problem was solved as a quasistatic problem and for numerical purposes, mass scaling was used.

\section{Cartilage}

Cartilage was modeled as an interaction between the surfaces of the bone in the acetabulum and the femoral head. Cartilage thickness in the hip joint of children have been measured to $5.41 \pm 0.17 \mathrm{~mm}$ by Hughes et al. and $2.59 \pm 0.41 \mathrm{~mm}$ by Spannow et al. [18,19]. Because of this large difference, models were created with an interaction thickness of either $5.0 \mathrm{~mm}$ or $2.7 \mathrm{~mm}$. The contact surfaces of both the acetabulum and the femoral head were picked by hand. For every node on each surface, the shortest distance to the opposite surface 

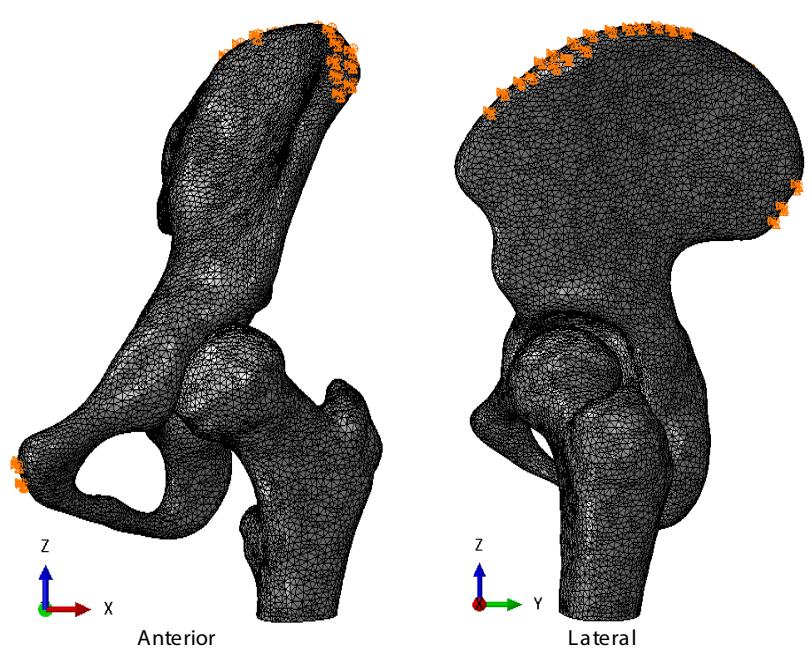

Figure 1: FE model of the hip joint in anterior and lateral view. Boundary conditions are marked in orange.

was extracted and used to calculate the resulting stress in the normal direction. Equation 1 expresses the normal stress in a hyper-elastic neo-Hookean material [20].

$$
\sigma=\frac{2 \mu(1+v)}{3}\left(\lambda^{-(5+2 v) / 3}\left(\lambda^{2+2 v}-1\right)+\lambda^{-2 v}\left(\lambda^{1-2 v}-1\right)\right)
$$

Here $\lambda=] 0,1]$, where $\lambda=\varepsilon+1$ with $\varepsilon$ being the engineering strain, $\varepsilon=\Delta \mathrm{l} / \mathrm{l}$. The material 134 properties used were shear modulus $\mu=6.8$ $\mathrm{MPa}$ and Poisson's ratio $v=0.490$ (Table 1 ).

\section{Verification}

For modeling surface pressure in an idealized joint, FE models with geometrical layers of cartilage, have previously been verified using analytical models $[21,22]$. To explore the effect of incorporating the cartilage into the interaction model, FE models of an idealized joint were constructed and compared. Cartilage was modeled by oneor two-layers of geometrical cartilage or an interaction (Figure 2). When subjecting the models to the same load, the contact area and pattern were compared. Contact areas were expressed as a percentage of the maximum area. For both the interaction model and the onelayer model, the rise in contact area is steep compared to the twolayer model (Figure 3). The interaction model reaches the maximum area in contact with a load of $100 \mathrm{~N}$ while the two-layer model reaches maximum as the load exceeds $400 \mathrm{~N}$. For the one-layer model, the contact area does not exceed $85 \%$ of the maximum possible area, but this is reached at a load of $150 \mathrm{~N}$. The contact pressure at the outer rim is low for the interaction and one-layer cartilage models compared to the two-layer cartilage model (Figure 4). In the two-layer model, a minimum is located in the center of the socket. The maximum contact pressure is similar for the interaction and two-layer cartilage models (1.05 and 1.06 $\mathrm{MPa}$ respectively), while it is higher for the one-layer model $(1.40 \mathrm{MPa})$. The low contact pressure in the center of the two-layer model and the higher pressure at the rim are more clear if the contact pressure is plotted with respect to the normalized distance from the center (Figure 5). Although the geometry is idealized, points of high pressure are locally seen in the models. This is caused by stress wave propagation in the explicit analyses, but is judged not to influence the overall response. Anderson et al. combined an experimental and a computational study to validate a FE model of the hip joint with respect to cartilage contact pressure and contact area [7]. Their cartilage consisted of two geometrical
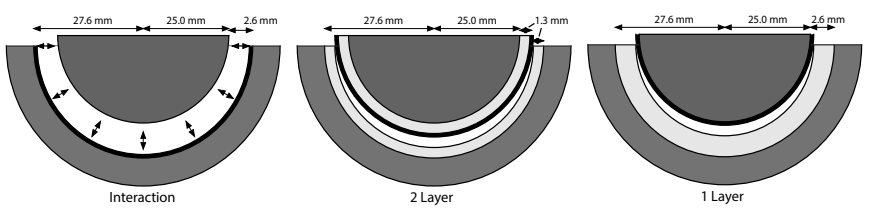

Figure 2: FE model of an idealized joint used for verification of the interaction. Model with cartilage modelled as an interaction (left), with two-layers of geometrical cartilage (middle), and with one-layer of geometrical cartilage (right). The dark grey region represents the bone; the light gray region is the cartilage, while the arrows represent the interaction. The black region shows the frictionless interface from where results were extracted.

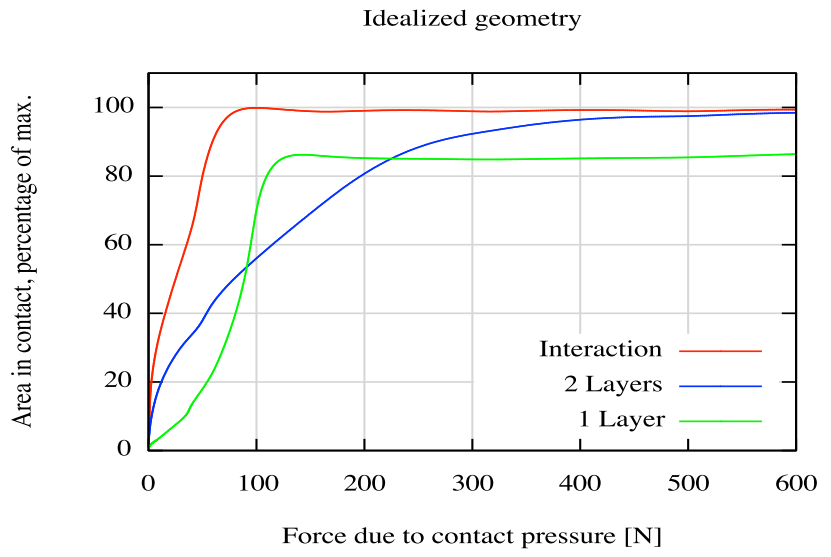

Figure 3: Contact area and force due to contact pressure in the model with an idealised geometry when modelling the cartilage as an interaction, two geometrical layers or one geometric layer. The contact area is expressed as a percentage of maximum possible contact area.
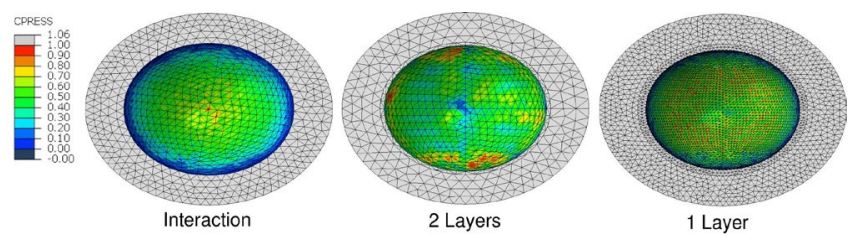

Figure 4: Contour plots of the contact pressure [MPa] in the socket model with an idealised geometry when modelling the cartilage as an interaction, two geometrical layers or one geometric layer. Maximum contact pressure were $1.05,1.06$ and $1.40 \mathrm{MPa}$ respectively for the three models.

layers with varying thickness. This approach may be considered to be the gold standard in FE modeling of the hip joint. Based on the observed behavior of the simplified joint model, the FE models of the actual hip geometry, incorporating the cartilage into the interaction, are expected to (1) overestimate area in contact with loads below $400 \mathrm{~N},(2)$ underestimate contact pressure at the outer rim and (3) overestimate contact pressure at the center of the socket.

\section{Results}

The model was loaded by $50-300 \%$ BW. As the load was increased, the area in contact in the hip joint was increased (Figure 6). At $233 \%$ BW the area in contact ranged from 351 to $405 \mathrm{~mm}^{2}$ depending on cartilage thickness and bone properties. At 50\% BW the area in contact ranged $120-198 \mathrm{~mm}^{2}$ while a load of $300 \%$ BW revealed a contact area of $407-521 \mathrm{~mm}^{2}$. 


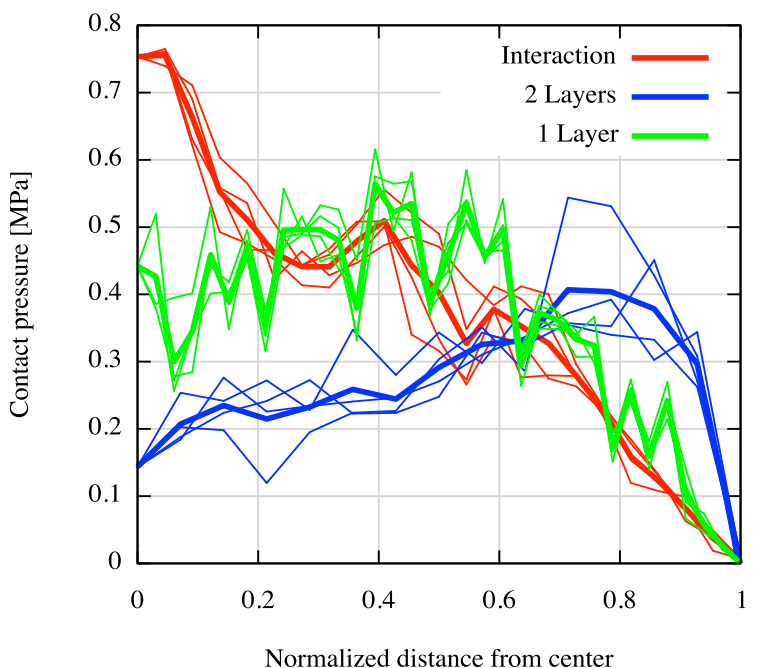

Figure 5: Readings of contact pressure from figure 4 expressed by the normalized distance from the center of the socket to the outer rim. Readings from $0^{\circ}, 90^{\circ}, 180^{\circ}$ and $270^{\circ}$ are plotted (thin lines), along with their averages (thick line).

At a load of $50 \%$ BW the contact pressure in the acetabulum did not exceed 5.7 MPa (Figure 7). As the load was increased the maximum contact pressure increased. Peak pressure was located in the superior, anterior part of the acetabulum for all four models. At a load of $300 \%$ BW the peak contact pressure reached 11.0-14.7 MPa and with a load of $233 \%$ BW peak pressures of 9.7-13.8 MPa were found. The result, when using adult properties for the bone, were compared against the results from using children's properties. A $30 \%$ softer bone resulted in an increase in contact area by $5-28 \%$ (Figure 6). The changes in contact pressure ranged from a decrease of $23 \%$ up to an increase of $15 \%$ (Figure 7). If cartilage thickness was decreased from $5.0 \mathrm{~mm}$ to $2.7 \mathrm{~mm}(46 \%)$ the area in contact decreased by up to $37 \%$ at $50 \%$ BW. At loads of $200 \%$ BW and above the differences were small. Changes in contact pressure were diverse and ranged from a decrease of $27 \%$ to an increase of $4 \%$.

\section{Discussion and Conclusion}

The aim of this project was to construct a FE model of the hip joint of a child using clinically recorded CT data. Cartilage is not visible in standard CT images thus another approach of modeling the cartilage was developed. Advantages of using CT data include fast segmentation of the bones and a fast clinical recording compared to MR (magnetic resonance), which is especially beneficial, when constructing models of smaller children. Comparing model predictions to previously reported experimental data from the literature is the most common way of validating computational biomechanical models.5 Disadvantages of this approach include differences between subjects and risk of misinterpretation of loading,

boundary conditions, and results. Several experimental studies have investigated the contact pressure and area in human hip joints, but, to the knowledge of the authors, not in the hip joint of a child. We expected a smaller area in contact because of the smaller geometry of a child's hip compared to an adult's.

\section{Validation}

Results were compared to experimental studies using similar loading conditions. Anderson et al. found an average contact area

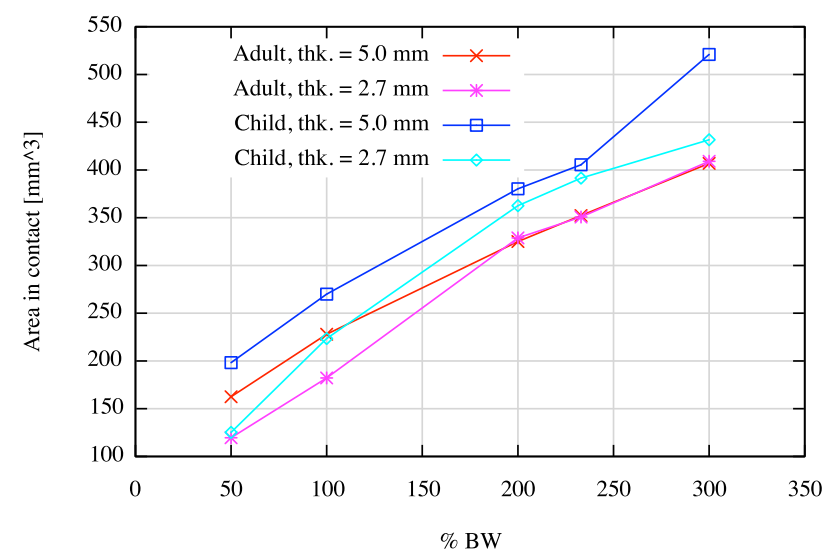

Figure 6: Area in contact with varying load and model definition.

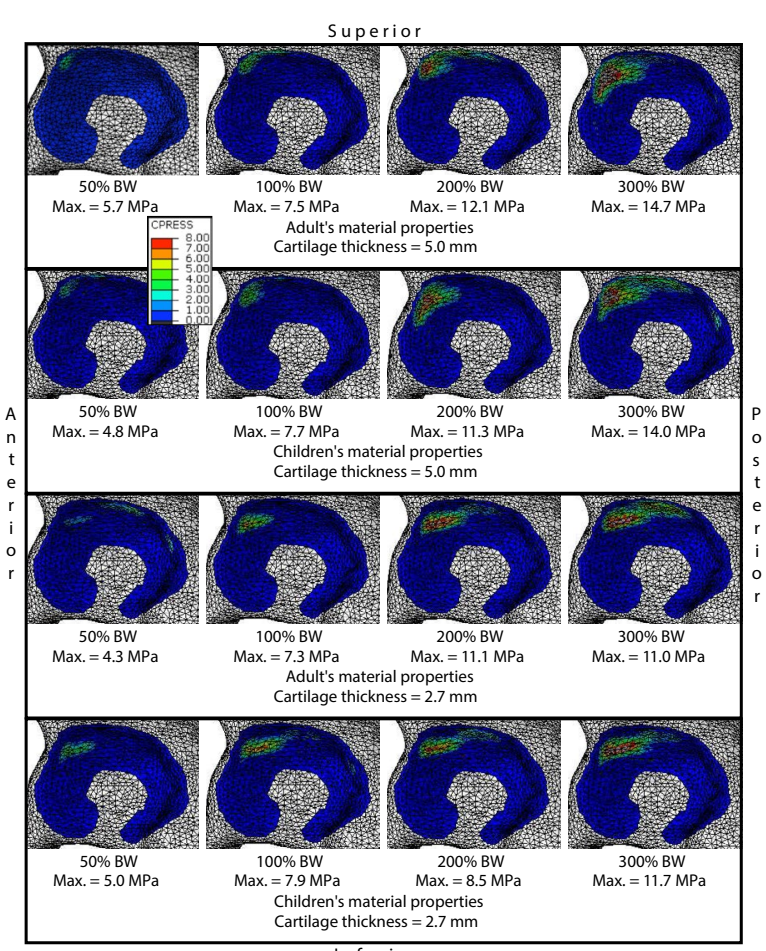

Figure 7: Contour plots of contact pressure with varying load and model definition.

of $425 \mathrm{~mm}^{2}$ during normal walking (233\% BW). As expected, this is larger than the 351 to $405 \mathrm{~mm}^{2}$ in the current study. Verification of the current method revealed a tendency to overestimate the area in contact with loads below $400 \mathrm{~N}$. Other computational hip models found contact areas ranging from 304 to $2233 \mathrm{~mm}^{2}$ revealing large variations among models and subjects (Table 3). von Eisenhart-Rothe et al. found peak pressure in the hip joint of $5 \mathrm{MPa}$ at $50 \% \mathrm{BW}$ and 9 $\mathrm{MPa}$ at $300 \% \mathrm{BW}$ in an experimental study [23]. At small loads, the current models agree with von Eisenhart-Rothe $(50 \% \mathrm{BW} \rightarrow 5.7 \mathrm{MPa})$, but at higher loads, peak pressures are higher (300\% BW $\rightarrow 11.0-14.7$ $\mathrm{MPa})$. A load of $233 \% \mathrm{BW}$ revealed peak contact pressures of 9.7-13.8 


\begin{tabular}{|c|c|c|c|c|c|}
\hline Experimental & Study & Hips & Loads & Peak pressure & $\begin{array}{l}\text { Area in a in } \\
\text { contact }\end{array}$ \\
\hline $\begin{array}{c}\text { Brown and Shaw } \\
{[20]}\end{array}$ & Cadaver & Normal, $n=17$, no info on labrum & Resultant joint load $=2.7 \mathrm{kN}$ & $8.80 \mathrm{MPa}$ & - \\
\hline Afoke et al. [2] & Cadaver & $\begin{array}{l}\text { Normal, } n=5 \text {, male }=2 \text {, age }=5886 \text {, } \\
\text { weight }=60-73 \mathrm{~kg} \text {, labrum removed }\end{array}$ & Walking $(3.3,1.3,4.1 \times \mathrm{BW})$ & 2.9-10.6 Mpa & - \\
\hline $\begin{array}{l}\text { von Eisenhart- } \\
\text { Rothe et al. [33] }\end{array}$ & Cadaver & Normal, $n=2$, male, age $=34,52$, labrum intact & Slow walking, $50-300 \%$ BW & 5-9 Мpa & - \\
\hline $\begin{array}{l}\text { von Eisenhart et } \\
\text { al. [33] }\end{array}$ & Cadaver & Healthy, $n=8$, age $=18-75$ labrum intact & Midstance, $345 \%$ BW & 3.75-9.75 Мpa & - \\
\hline $\begin{array}{l}\text { Anderson et } \\
\text { al. [6] }\end{array}$ & Cadaver & $\begin{array}{c}\text { Normal, } \mathrm{n}=1, \text { male, age }=25, \text { weight }=82 \mathrm{~kg}, \\
\text { labrum removed }\end{array}$ & Avg. normal walking & $1.7-10.0 \mathrm{kMPa}$ & $\begin{array}{l}425.1 \mathrm{~mm}^{2} \text { (entire } \\
\text { range) }\end{array}$ \\
\hline Computational & Study & Hips & Load & Peak pressure & Area in contact \\
\hline $\begin{array}{l}\text { Bachtar et al. } \\
{[17]}\end{array}$ & FE, cadaver, & $\begin{array}{c}\text { Normal, } \mathrm{n}=1, \text { female, age }=71, \text { weight }=41 \mathrm{~kg}, \\
\text { no labrum }\end{array}$ & Normal walking (avg.) & $\begin{array}{c}5.50 \mathrm{MPa}-(\mathrm{at} \approx 200 \% \\
\mathrm{BW})\end{array}$ & - \\
\hline \multirow{3}{*}{ Russel et al. [34] } & \multirow{3}{*}{$\begin{array}{l}\text { FE, CT with } \\
\text { contrast }\end{array}$} & $\begin{array}{c}\text { Normal, } \mathrm{n}=1 \text {, male, age }=38, \text { weight }=90 \mathrm{~kg} \text {, } \\
\text { no labrum }\end{array}$ & \multirow{3}{*}{$\begin{array}{c}\text { Gait (stance phase) of } 67 \mathrm{~kg} \mathrm{72-year-old} \\
\text { male }\end{array}$} & $1.75 \mathrm{Mpa}$ & $2233 \mathrm{~mm}^{2}$ \\
\hline & & $\begin{array}{l}\text { Dysplastic, } n=6, \text { male }=1 \text {, age }=28-53 \\
\text { weight }=51-74 \mathrm{~kg} \text {, no labrum }\end{array}$ & & $6.59 \pm 1.90 \mathrm{Mpa}$ & $569 \pm 97 \mathrm{~mm}^{2}$ \\
\hline & & $\begin{array}{c}\text { Asymptomatic, } \mathrm{n}=5 \text {, male=1, age }=28-53 \text {, } \\
\text { weight }=51-74 \mathrm{~kg} \text {, no labrum }\end{array}$ & & $5.25 \pm 1.02 \mathrm{Mpa}$ & $663 \pm 55 \mathrm{~mm}^{2}$ \\
\hline $\begin{array}{l}\text { Anderson et } \\
\text { al. [2] }\end{array}$ & FE, cadaver, & $\begin{array}{c}\text { Normal, } \mathrm{n}=1, \text { male, age }=25, \text { weight }=82 \mathrm{~kg} \text {, } \\
\text { no labrum }\end{array}$ & Avg. normal walking & $10.78 \mathrm{MPa}$ & $304 \mathrm{~mm}^{2}$ \\
\hline Harris et al. [8] & $\begin{array}{l}\text { FE, CT with } \\
\text { contrast }\end{array}$ & Healthy, $n=10$, male $=5$, age $=26+4$, no labrum & Daily activities (avg.) & $7.16 \pm 2.62 \mathrm{Mpa}$ & $\begin{array}{c}657+43 \mathrm{~mm}^{2} \\
\text { (total }=1936+ \\
295)\end{array}$ \\
\hline \multirow[t]{2}{*}{$\begin{array}{l}\text { Abraham et } \\
\text { al. [2] }\end{array}$} & \multirow[t]{2}{*}{$\begin{array}{l}\text { DEA, cadaver/ } \\
\text { FEA, cadaver }\end{array}$} & \multirow[t]{2}{*}{$\begin{array}{c}\text { Normal, } \mathrm{n}=1, \text { male, age }=25 \text {, weight }=82 \mathrm{~kg} \text {, no } \\
\text { labrum, rigid bones }\end{array}$} & \multirow[t]{2}{*}{ Daily activities (avg.) } & 9.8-13.6 Мpa & $870-1220 \mathrm{~mm}^{2}$ \\
\hline & & & & 6.2-9.8 Мpa & $900-1320 \mathrm{~mm}^{2}-$ \\
\hline \multirow{4}{*}{ Current study } & \multirow{4}{*}{ FE, clinical CT } & \multirow{4}{*}{$\begin{array}{c}\text { Asymptomatic, } n=1, \text { girl, age }=10 \text { weight }=32, \\
\text { no labrum }\end{array}$} & \multirow[t]{2}{*}{ Max. during normal walking $233 \%$ BW } & \multirow[t]{2}{*}{ 9.7-13.8 Мра } & $351-405 \mathrm{~mm}^{2}$ \\
\hline & & & & & $351-405 \mathrm{~mm}^{2}$ \\
\hline & & & $50 \%$ BW & 4.3-5.7 Mpa & $120-198 \mathrm{~mm}^{2}$ \\
\hline & & & $300 \%$ BW & 11.0-14.7 Мра & $407-521 \mathrm{~mm}^{2}$ \\
\hline
\end{tabular}

Table 3: Computational and experimental studies concerning cartilage contact forces. Computational models are only included is they are based on subject specific anatomy and modeled in 3 dimensions.

MPa in the current study. This is in agreement with an experimental study by Anderson et al. that found contact pressures to exceed 10 $\mathrm{MPa}$ at 233\% BW [7]. Abraham et al. used a similar approach for modeling cartilage with discrete element analysis (DEA) but with position dependent cartilage thickness and rigid bones [24]. DEA estimated higher contact stresses and lower contact area compared to a FE model with hyperelastic cartilage and rigid bones. Unfortunately, they did not evaluate their model against a FE model with elastic bones despite Anderson et al. demonstrated that assuming rigid bones might alter cartilage contact stresses in the hip joint [7]. Anderson et al. investigated the impact of several common simplifications in FE models [25]. Using a model with subject-specific bone geometry, cartilage thickness, and bone material properties as the gold standard, they found models with constant cartilage thickness to overestimate contact cartilage pressure and underestimate contact area. Keeping this in mind, we expected the current models to overestimate peak pressures and reveal a smaller area in contact compared to other studies. When reviewing published studies, both experimental and computational, this was true in most cases (Table 3). Differently from other studies, the bone geometry from a 10-year-old girl's hip was used. This revealed several challenges. Than et al. evaluated radiographic parameters of the hip joint from birth to adolescence. At 10 -years of age, $70 \%$ had the center of the femoral head located inside the acetabulum entrance, while at 16-years of age the number was $95 \%$. Therefore, the current model was less stable than a model of a mature hip. These challenges were overcome by applying springs around the hip joint. In the CT data, the femoral growth plate and Y-cartilage in the acetabulum were visible. The bone geometry was incomplete when automatic segmentation by threshold was used, and manual adjustment was necessary. Material properties of growth plates resemble that of cartilage [26]. For evaluation purposes, the growth plates were omitted to simulated a scenario as close to the adult hip as possible. Soft tissues such as cartilage or labrum is not visible in standard CT data. Most experimental studies and computational 
models regarding the hip joint have removed labrum (Table 3). Henak et al. investigated the impact of including or removing labrum in $\mathrm{FE}$ models [27]. In a normal hip, the load supported by the labrum was limited, but in a dysplastic hip, the labrum did support a significant amount of load. It is possible that labrum and other soft tissues do provide a considerable amount of support in the pediatric hip joint as well, but we compensated for this by applying supporting springs. The current model was constructed with subject specific bone geometry while the cartilage thickness was assumed to be constant. Because of discrepancies in the literature concerning cartilage thickness in the hip joints of children, a thickness of either 2.7 or $5.0 \mathrm{~mm}$ were used $[19,20]$. Because of the lack of an appropriate experimental study for validation purposes, it was not possible to determine which of the constant thicknesses that provides the most realistic response. In general, the thicker cartilage revealed a larger area in contact, but also a higher peak pressure. Kim et al. constructed a FE model of the pelvis of a 10-year old child and used an experimental study to adjust the material properties from an adult's to a child's [25]. Their updated bone material properties were in accordance with the findings by Currey and Butler [28]. Due to different loading conditions it was not possible to compare findings from their study with the majority of FE studies concerning hip joints. In the current study, we used the same loading conditions as the majority of similar studies, why it is not possible to compare our results to Kim et al. [18] The outer geometry of the bone was subject specific, but the thickness of the cortical bone was estimated in this study. Both Dalstra et al. [29] and Anderson et al. [30] combined an experimental study with a FE model of the pelvis modeled with either mean or position dependent cortical bone thickness $[5,6]$. For predicting von Mises stress in the cortical bone, a FE model with position-dependent cortical thickness performed better, though not significantly [6]. Joint mechanics was not investigated. Therefore, the impact of using an even cortical bone thickness is unclear when the output parameters are contact area and contact pressure in the hip joint.

Although the current model was constructed from an asymptomatic hip that was deemed normal, the other hip was slightly dysplastic. Russel et al. used FE models to compare cartilage contact pressures in symptomatic $(n=6)$ and asymptomatic $(n=5)$ hips in patients with dysplasia [10]. They concluded that although an asymptomatic hip appears normal on plane radiographs, the cartilage contact pressure cannot be assumed to be normal. Harris et al. [31,32] used FE models to investigate the contact stresses in 12 normal, healthy human hips and found greater variation among subjects than among loading scenarios [19]. An experimental study by Dalstra et al. used both the left and right hip from the same subject and found large left/right differences in cortical principal stresses $[17,33,34]$. Even in normal, healthy hips, large variations among subjects are therefore to be expected. In conclusion, we have created a FE model of the hip joint of a child from a clinical recorded CT. The impact of changing material properties of bone or the thickness of the cartilage was limited if the output was contact area or pressure. The models showed good correlation to experimental studies, when using loading conditions as close to experimental as possible. For comparison of several hips, the current method is relevant, because it is relatively fast to construct a new model from CT data.

\section{Conflict of Interest}

We gratefylly acknowledge financial support from the Lundbeck Foundation, Elsass Foundation, Dagmar Marshall Foundation, Axel Muusfeldt Foundation, Direktør Jacob Madsenog Hustru Olga Madsen Foundation and RegionH.

\section{Acknowledgment}

We thank R. Salmingo, M. Traberg and K. Henneberg from Department of Electrical Engineering at the Technical University of Denmark for support with segmentation of the models.

\section{References}

1. Helwig P, Hindenlang U, Hirschmu“ller A, Konstantinidis L, Su“dkamp N, et al. (2011) A femoral model with all relevant muscles and hip capsule ligaments. Comput Methods Biomech Biomed Engin 16: 669-677.

2. Harris M, Anderson A, Henak C, Ellis B, Peters C, et al. (2012) Finite element prediction of cartilage contact stresses in normal human hips. J Orthop Res 30: 1133-1139.

3. Li G, Sakamoto M, Chao E (1997) A comparison of different methods in predicting static pressure distribution in articulating joints. J Biomech 30: 635638.

4. Ohman C, Baleani M, Pani C, Taddei F, Alberghini M, et al. (2011) Compressive behaviour of child and adult cortical bone. Bone 49: 769-776.

5. Gosvig K, Jacobsen S, Sonne-Holm S, Palm H, Troelsen A (2010) Prevalence of malformations of the hip joint and their relationship to sex, groin pain, and risk of osteoarthritis: A population-based survey. J Bone Joint Surg Am 92 1162-1169.

6. Anderson A, Peters C, Tuttle B, Weiss J (2005) Subject-specific finite element model of the pelvis: Development, validation and sensitivity studies. J Biomech Eng 127: 364-373.

7. Anderson A, Ellis B, Maas S, Peters C, Weiss J (2008) Validation of finite element predictions of cartilage contact pressure in the human hip joint. $J$ Biomech Eng 130: 051008

8. Harris W (1986) Etiology of osteoarthritis of the hip. Clin Orthop Relat Res, pp: 20-33.

9. Klit J, Gosvig K, Jacobsen S, Sonne-Holm S, Troelsen A (2011) The prevalence of predisposing deformity in osteoarthritic hip joints. Hip Int 21: 537-541.

10. Spannow A, Stenboeg E, Pfeier-Jensen M, Herlin T (2007) Ultrasound measurement of joint cartilage thickness in large and small joints in healthy children: A clinical pilot study assessing observer variability. Pediatr Rheumato Online J 5: 3.

11. Mavcic B, Iglic A, Kralj-Iglic A, Brand R, Vengust R (2008) Cumulative hip contact stress predicts osteoarthritis in $\mathrm{DDH}$. Clin Orthop Relat Res 466: 884 891.

12. Brown C, Nguyen T, Moody H, Crawford R, Oloyede A (2009) Assessment of common hyperelastic constitutive equations for describing normal and osteoarthritic articular cartilage. Proc Inst Mech Eng H 223: 643-652.

13. Hughes L, Aronson J, Smith $\mathrm{H}$ (1999) Normal radiographic values for cartilage thickness and physeal angle in the pediatric hip. J Pediatr Orthop 19: 443-448.

14. Wirtz D, Schiers N, Pandorf T, Radermacher K, Weichert D, et al. (2000) Critical evaluation of known bone material properties to realize anisotropic FEsimulation of the proximal femur. J Biomech 33: 1325-1330.

15. Eisenhart VR, Adam C, Steinlechner M, Müller-Gerbl M, Eckstein F (1999) Quantitative determination of joint incongruity and pressure distribution during simulated gait and cartilage thickness in the human hip joint. J Orthop Res 17: 532-539.

16. Bergmann G, Deuretzbacher G, Heller M, Graichen F, Rohlmann A, et al (2001) Hip contact forces and gait patterns from routine activities. J Biomech 34: 859-871.

17. Bachtar F, Chen X, Hisada T (2006) Finite element contact analysis of the hip joint. Med Biol Eng Comput 44: 643-651.

18. Kim JE, Li Z, Ito Y, Huber C, Shih A, et al. (2009) Finite element mode development of a child pelvis with optimization-based material identification. $J$ Biomech 42: 2191-2195

19. Than P, Sillinger T, Kranicz J, Bellyei A (2004) Radiographic parameters of the hip joint from birth to adolescence. Pediatr Radiol 34: 237-244.

20. Brown T, Shaw D (1983) In vitro contact stress distributions in the natura human hip. J Biomech 16: 373-384.

21. Bartel D, Burstein A, Toda M, Edwards D (1985) The efect of conformity and plastic thickness on contact stresses in metal-backed plastic implants. J Biomech Eng 107: 193-199. 
Citation: Skytte TL, Mikkelsen LP, Sonne-Holm S, Wong C (2017) Using a Finite Element Pediatric Hip Model in Clinical Evaluation - A Feasibility Study. J Bioengineer \& Biomedical Sci 7: 241. doi: 10.4172/2155-9538.1000241

Page 7 of 7

22. Majumder S, Roychowdhury A, Pal S (2007) Simulation of hip fracture in sideways fall using a $3 \mathrm{D}$ finite element model of pelvis-femur-soft tissue complex with simplified representation of whole body. Med Eng Phys 29: 11671178.

23. Wiberg G (1939) Studies on dysplastic acetabula and congenital subluxation of the hip joint with special reference to the complication of osteo-arthritis. Acta Chir Scand.

24. Abraham C, Maas S, Weiss J, Ellis B, Peters C, et al. (2013) A new discrete element analysis method for predicting hip joint contact stresses. J Biomech 46: 1121-1127.

25. Anderson A, Ellis B, Maas S, Weiss J (2010) Efects of idealized joint geometry on finite element predictions of cartilage contact stresses in the hip. J Biomech 43: $1351-1357$.

26. Currey J, Butler G (1975) The mechanical properties of bone tissue in children. J Bone Joint Surg Am 57: 810-814.

27. Hilgenreiner $\mathrm{H}$ (1925) For the early diagnosis and early treatment of the innate hip joint dislocation (In German). Med Klin 21: 1385.

28. Dalstra M, Huiskes R, Odgaard A, Van Erning L (1993) Mechanical and textural properties of pelvic trabecular bone. J Biomech 26: 523-535.

29. Dalstra M, Huiskes R, Van Erning L (1995) Development and validation of a three-dimensional finite element model of the pelvic bone. J Biomech Eng 117 272-278.

30. Anderson A, Ellis B, Weiss $\mathrm{J}$ (2007) Verification validation and sensitivity studies in computational biomechanics. Comput Methods Biomech Biomed Engin 10: 171-184.

31. Henak C, Ellis B, Harris M, Anderson A, Peters C, et al. (2011) Role of the acetabular labrum in load support across the hip joint. J Biomech 44: 22012206.

32. Bergmann G, Graichen F, Rohlmann A (1993) Hip joint loading during walking and running, measured in two patients. J Biomech 26: 969-990.

33. Eisenhart-Rothe VR, Eckstein F, Müller-Gerbl M, Landgraf J, Rock C, et al (1997) Direct comparison of contact areas, contact stress and subchondral mineralization in human hip joint specimens. Anat Embryol 195: 279-288.

34. Russell M, Shivanna K, Grosland N, Pedersen D (2006) Cartilage contact pressure elevations in dysplastic hips: a chronic overload model. J Orthop Surg Res 1: 6. 